\title{
PEMANFATAAN BOTOL PLASTIK BEKAS SEBAGAI MEDIA TANAM HIDROPONIK DALAM MENINGKATKAN KESADARAN SISWA SEKOLAH DASAR TERHADAP LINGKUNGAN SEKITAR
}

\author{
Haifaturrahmah ${ }^{1}$, Muhammad Nizaar ${ }^{2}$, Mas'ad $^{3}$ \\ 1, 2 PGSD, ${ }^{3}$ Pendidikan Geografi, Universitas Muhammadiyah Mataram, \\ haifaturrahmah@yahoo.com
}

\begin{abstract}
ABSTRAK
Abstrak: Dari sekian limbah rumah tangga ada yang sangat berbahaya bagi lingkungan dan kesehatan manusia yaitu sampah anorganik khususnya sampah plastik, yang keberadaannya kadang dianggap kecil. Plastik memang salah satu 'musuh' terbesar lingkungan, botol plastik bekas minuman dalam kemasan salah satunya. Seperti yang diketahui bahwa plastik berdampak buruk bagi lingkungan karena sifat plastik yang memang susah diuraikan oleh tanah meskipun sudah tertimbun bertahuntahun. Pemanfaatan sampah anorganik adalah salah satu yang bisa dilakukan oleh seluruh masyarakat untuk menjaga kelestarian lingkungan. Salah satu cara sederhana yang dapat diterapkan di sekolah dasar untuk meningkatkan kesadaran siswa terhadap lingkungan yaitu memanfaatkan botol plastik bekas sebagai media tanam dengan menggunakan konsep hidroponik sumbu atau sistem wick.
\end{abstract}

Kata Kunci: Lingkungan, Botol Plastik Bekas, Hidroponik

Abstract: Of the many household wastes are very harmful to the environment and human health, namely inorganic waste, especially plastic waste, whose existence is sometimes considered small. Plastic is indeed one of the 'enemies' biggest environmental, plastic bottles used in beverage packaging one of them. As is known that the plastic is bad for the environment because of the plastic that is difficult to decipher the soil even though it has been buried for years. Utilization of inorganic waste is one that can be done by the whole community to preserve the environment. One simple way that can be applied in elementary school to increase awareness of students to the environment that is utilizing used plastic bottles as a media planting using the concept of hydroponic wick system.

Keywords: Environment, Waste Plastic Bottles, Hydroponics

Riwayat Artikel: Diterima: 01-12-2017, Disetujui: 15-12-2017 


\section{A. PENDAHULUAN}

Desa Saribaye merupakan salah satu desa dari 10 (sepuluh) desa yang ada di Kecamatan Lingsar, dan merupakan desa terkecil dengan luas 134.05 Ha. Desa Saribaye berdasarkan fakta geografis merupakan desa pertanian (agraris), akan tetapi yang perlu diketahui bahwa sebagian besar pemilik lahan pertanian di Desa Saribaye merupakan hak milik/dikuasai oleh warga yang berasal dari luar wilyah Desa Saribaye termasuk Universitas Mataram, sehingga penduduk yang bermata pencaharian sebagai petani sangat minim. Mata pencaharian penduduk Desa Saribaye yang sangat dominan adalah buruh tani dan buruh lepas, pedagang baru kemudian petani.

Pola penggunaan lahan di Desa Saribaye sebagian besar di gunakan untuk tanah persawahan dan permukiman. Lahan yang digunakan sebagai tempat pemukiman sekitar $6 \mathrm{Ha}$ dari total keseluruhan lahan di Desa Saribaye, meskipun termasuk desa yang kecil akan tetapi merupakan pemukiman yang padat. Ledakan jumlah penduduk yang pesat memberikan kontribusi perluasan lahan perumahan sebagai tempat tinggalnya. Dimana semakin luas suatu daerah pemukiman maka semakin besar pula masalah yang ditimbulkan. Salah satu permasalahan dari pemukiman yang padat adalah sampah. Sampah adalah zat atau bahan yang sudah tidak berguna lagi dan sudah semestinya untuk dibuang [5].

Sampah dapat digolongkan menjadi dua, yaitu sampah organik dan anorganik. Menurut Slamet (2010), sampah organik adalah sampah yang dapat membusuk seperti sisa makanan, sampah kebun maupun sampah pertanian. Sedangkan sampah anorganik adalah sampah yang tidak dapat membusuk seperti sampah karet, gelas, logam dan plastik [4].

Sampah rumah tangga yang tidak tertangani kian menumpuk, khususnya permasalahan sampah plastik. Plastik memang salah satu 'musuh' terbesar lingkungan, botol plastik bekas minuman dalam kemasan salah satunya. Penggunaan botol plastik semakin marak di kalangan masyarakat, seakan sudah menjadi budaya untuk mengkonsumsi minuman dalam kemasan tersebut. Setelah botol plastik dibuang pemakainya, hampir semua botol akan berakhir di tempat pembuangan sampah. Jika sampah tersebut terus dibiarkan, tentu akan menimbulkan dampak serius bagi lingkungan yang mengakibatkan pencemaran udara, tanah dan dapat menyebabkan banjir.

Seperti yang diketahui bahwa plastik berdampak buruk bagi lingkungan karena sifat plastik yang memang susah diuraikan oleh tanah meskipun sudah tertimbun bertahun-tahun. Sampah dapat menjadikan masalah dan juga dapat bermanfaat dalam menguatkan ekonomi masyarakat. Sampai saat ini peran serta masyarakat secara umum hanya sebatas pembuangan sampah saja belum sampai pada tahapan pengelolaan sampah yang dapat bermanfaat kembali bagi masyarakat Pengelolaan sampah merupakan perlakuan terhadap sampah untuk memperkecil masalah yang timbulkan 
pada lingkungan. Oleh karena itu, pengelolaan sampah dapat berbentuk membuang sampah atau mengembalikan sampah menjadi bahan yang bermanfaat.

Secara umum, pelaksanaan pekerjaan perencanaan teknis pengelolaan sampah terpadu 3R (reuse, reduce, recycle) yaitu menggunakan kembali sampah secara langsung, mengurangi segala sesuatu yang menyebabkan timbulnya sampah, memanfaatkan kembali sampah setelah mengalami proses pengolahan. Salah satu cara sederhana pengolahan sampah yang dapat dilakukan adalah dengan teknis reuse, yaitu memanfaatkan botol plastik bekas yang ada dilingkungan sekitar seperti botol air mineral sebagai media tanam dengan menggunakan konsep hidroponik sumbu atau sistem wick.

Hidroponik adalah sistem budidaya yang menggunakan air sebagai media utamanya, tanaman bisa tumbuh dengan baik tanpa menggunakan tanah. Penggunaan konsep hidroponik sumbu merupakan salah satu cara sederhana yang dapat diterapkan di sekolah dasar untuk meningkatkan kesadaran siswa terhadap lingkungan dengan memanfaatkan botol plastik bekas. Berdasarkan hal yang sudah dipaparkan tersebut maka pengusul mengangkat topik pengabdian pada masyarakat dengan judul "Pemanfataan Botol Plastik Bekas Sebagai Media Tanam Hidroponik dalam Meningkatkan Kesadaran Siswa Sekolah Dasar terhadap Lingkungan Sekitar"

\section{B. METODEPELAKSANAAN}

\section{Metode Pelaksanaan}

Kegiatan ini dilakukan menggunakan metode praktikum dan pelaksanaan dilakukan di SD Negeri 1 Saribaye, Kecamatan Lingsar, Kabupaten Lombok Barat. Lokasi Desa Saribaye ini bisa ditempuh dengan sepeda motor maupun kendaraan roda empat yang terletak 1 $\mathrm{Km}$ ke arah Utara dari kota Mataram. Adapun mitra dalam kegiatan ini adalah siswa yang menjadi anggota kegiatan pramuka sebanyak 40 siswa.

\section{Tahap Pelaksanaan}

Berikut ini adalah tahapan dari pelaksanaan kegiatan pembuatan media tanam hidroponik dengan memanfaatkan botol plastik bekas.

a. Berkomunikasi dengan kepala sekolah dan guru pembina pramuka.

b. Tim menyediakan bibit dan nutrisi tanaman hidroponik.

c. Tim bersama siswa pramuka mengumpulkan botol plastik.

d. Tim memberikan pengarahan dan pelatihan kepada para siswa untuk:

1) membuat media tanam hidroponik dari botol plastik bekas,

2) menanam bibit pada media tanam,

3) menjaga dan merawat tanaman agar tumbuh dan berkembang dengan baik. 


\section{PEMBAHASAN}

Kegiatan ini telah dilaksanakan mulai tanggal 12 Oktober - 18 November 2017, dirangkaikan dengan realisasi program mahasiswa KKN. Adapun rincian kegiatan sesuai Tabel 1 di bawah ini.

TABEL 1

WAKTU EFEKTIF PELAKSANAAN PENGABDIAN

\begin{tabular}{cll}
\hline No & \multicolumn{1}{c}{ Kegiatan } & \multicolumn{1}{c}{ Pelaksanaan } \\
\hline 1 & Survey lapangan & $12-14$ Oktober 2017 \\
2 & Pengumpulan alat dan bahan & $15-19$ Oktober 2017 \\
3 & Pembuatan media tanam & 20 Oktober 2017 \\
4 & Pengamatan dan perawatan & 21 Oktober -17 November 2017 \\
5 & Pelaporan & 18 November 2017 \\
\hline
\end{tabular}

Tahap awal yang dilakukan sebelum melakukan kegiatan ini adalah mengobservasi keadaan di lingkungan sekitar sekolah. Hasil observsi selama tiga hari sejak tanggal $12-14$ oktober 2017, tim pengabdian menemukan masalah halaman sekolah yang didominasi oleh paving block sehingga keadaan sekolah tidak asri dan tampak kering, dan sampah plastik dari bungkusan/ wadah makanan dan minuman siswa yang beserakan di halaman sekolah.

Dari hasil observasi tersebut, tim pengabdian memutuskan melakukan penghijuan terhadap lingkungan sekolah dengan memanfaatkan sampah plastik, dalam hal ini adalah memanfaatkan botol plastik bekas yang digunakan sebagai media tanam. Sistem budidaya yang paling tepat dan sederhana untuk diterapkan pada siswa sekolah dasar sekaligus untuk meningkatkan kesadaran siswa terhadap lingkungan adalah sistem budidaya hidroponik, yang merupakan sistem budidaya menggunakan air sebagai media utama menggantikan fungsi tanah. Pemilihan menggunakan sistem hidroponik di lingkungan sekolah selain untuk memanfaatkan botol plastik bekas dan juga untuk menghindari kecenderungan siswa yang sering menginjak tanaman di taman sekolah karena tanaman dapat digantung atau bahkan menempel ditembok sekolah.

Hal pertama yang harus dilakukan oleh siswa dalam kegaiatan ini adalah mengumpulkan alat dan bahan yang akan digunakan untuk sistem hidroponik. Bahan utama yang paling dibutuhkan adalah botol plastik bekas yang diperoleh dari lingkungan sekitar sekolah. Selain itu, bahan yang lainnya adalah bibit dan nutrisi tanaman. Bibit tanaman yang digunakan adalah bibit kangkung, agar dapat dipanen dan dimanfaatkan oleh warga sekolah.

Sasaran kegiatan pemanfaatan botol plastik bekas sebagai media tanam hidrponik adalah para siswa yang menjadi anggota pramuka di SD Negeri 1 Saribaye. Pemilihan sasaran mitra anggota pramuka adalah karena sesuai dengan tujuan dari pembentukan kepramukaan, salah satunya dalah menggerakkan anggota pramuka agar peduli dan tanggap terhadap 
masalah-masalah kemasyarakatan. Sehingga memantapkan jati diri pramuka melalui kode kehormatannya dan sekaligus sebagai pencerminan anggota pramuka yang tanggap terhadap permasalahan pada lingkungan sekitarnya [3]. Meskipun kegiatan ini tidak melibatkan semua siswa dari kelas I - VI namun melalui semua anggota pramuka di SD Negeri 1 Saribaye dapat memberikan contoh tentang kesadaran akan lingkungan khususnya pada siswa lainnya dan secara umum pada masyarakat sekitar.

Pendidikan lingkungan hidup yang kita kenal adalah pendidikan yang diberikan secara formal mulai dari sekolah dasar sampai dengan perguruan tinggi untuk mengenal lingkungan, baik itu adalah dampak positif maupun dampak negatif dari limbah rumah tangga yang dihasilkan oleh masyrakat itu sendiri [6]. Dari sekian limbah rumah tangga ada yang sangat berbahaya bagi lingkungan dan kesehatan manusia yaitu sampah anorganik khususnya sampah plastik yang keberadaannya kadang dianggap kecil.

Pencemaran lingkungan akibat sampah plastik semakin mengkhawatirkan apabila tidak ada usaha untuk mengatasinya. Hampir setiap orang pasti tidak akan terlepas dari namanya bahan plastik dalam aktivitasnya sehari-hari. Seperti yang diketahui bahwa plastik berdampak buruk bagi lingkungan karena sifat plastik yang memang susah diuraikan oleh tanah meskipun sudah tertimbun bertahun-tahun.

Pemanfaatan sampah plastik adalah salah satu yang bisa dilakukan oleh seluruh masyarakat untuk menjaga kelestarian lingkungan, khususnya siswa sekolah dasar. Cara sederhana yang dapat diterapkan di sekolah dasar adalah memanfaatkan botol plastik bekas sebagai media tanam dengan sistem hidroponik, khususnya dengan sistem sumbu atau wick. Kegiatan ini selain untuk meningkatkan kesadaran lingkungan bagi siswa sejak dini, dan juga dapat dimanfaatkan sebagai media pembelajaran. Dimana siswa mampu memahami tentang proses perkembangan dan pertumbuhan pada tumbuhan, memahami pentingnya sinar matahari sebagai sumber energi dalam proses fotosintesis, memiliki pengetahuan baru bahwa tumbuhan dapat tumbuh tanpa media tanah melainkan hanya dengan menggunakan media air dan yang paling penting adalah miningkatkan kepekaan siswa terhadap penggunaan produk yang terbuat dari plastik dan memanfaatan sampah yang berasal dari plastik sehingga membantu dalam mengurangi sampah plastik.

\section{TEMUAN}

Selama pelaksanaan kegiatan pengabdian terdapat beberapa temuan permasalahan lain yakni siswa - siswi masih menggunakan bahasa daerah (lokal), sehingga menyulitkan dalam mentransformasi pelajaran yang diterima, dan pihak sekolah belum menyiapkan tempat sampah yang memisahkan sampah organik dan anorganik. Hal ini menyulitkan siswa dalam proses pengumpulan botol plastik bekas yang terdapat dilingkungan 
sekolah untuk dimanfaatkan sebagai media tanam hidroponik. Selain itu, temuan kendala yang paling berpengaruh dalam proses pertumbuhan dan perkembangan tanaman dengan media hidropinik adalah faktor cuaca. Selama proses kegiatan berlangsung, faktor cuaca dengan instensitas curah hujan yang cukup tinggi menyebabkan pertumbuhan bibit tanaman tidak dapat tumbuh dengan maksimal.

\section{E. SIMPULAN DAN SARAN}

\section{Simpulan}

Adapun beberapa simpulan yang diperoleh dari kegiatan ini sebagai berikut:

a. Siswa sangat antusias dengan kegiatan ini karena memiliki pengetahuan baru bahwa tanaman dapat tumbuh tanpa media tanah akan tetapi hanya dengan menggunakan media air (hidroponik).

b. Melalui kegiatan ini menunjukkan kepada siswa bahwa botol plastik bekas dapat dimanfaatkan secara sederhana yaitu sebagai media tanam hidrponik.

\section{Saran}

Adapun saran yang dapat diberikan berdasarkan hasil pengabdian ini adalah sebagai berikut:

a. Pihak sekolah hendaknya membuat tempat sampah untuk memisahkan sampah organik dan anorganik, sehingga memudahkan siswa untuk mendaur ulang atau memanfaatkan kembali menjadi barang yang layak pakai.

b. Perlu kegiatan lebih lanjut dengan skala besar dengan melibatkan masyarakat sekitar. Jika masyarakat dapat mengolah sampah dengan benar, maka akan mengurangi pencemaran lingkungan dan mendapatkan nilai ekonomi yang baik.

\section{UCAPAN TERIMA KASIH}

Keberhasilan pelaksanaan kegiatan ini tidak terlepas dari dukungan Universitas Muhammadiyah Mataram melalui Lembaga Pengabdian Pada Masyarakat (LPPM) yang telah mendanai kegiatan pengabdian ini sehingga terlaksana dengan baik.

\section{DAFTAR RUJUKAN}

[1] DP2M Dikti, Buku Panduan Pelaksanaan Penelitiandan Pengabdian Kepada Masyarakat Edisi XI Tahun 2017. Jakarta.

[2] LPM UM Mataram, Pedoman Pengabdian Kepada Masyarakat dan Prosedur Penulisan Proposal. Universitas Muhammadiyah Mataram. 
[3] Maftuh, Asep Mochamad., Buku Pegangan Pembinan Pramuka, MTs Daruuslam, Cimahi, 2008.

[4] Slamet, Klasifikasi dan Penggolongan Jenis Sampah, Gramedia, Jakarta, 2010.

[5] Suryati, Teti., Bijak dan Cerdas Mengolah Sampah, Agromedia, Jakarta, 2009.

[6] Tim KLH, Pembelajaran Lingkungan Hidup Pada Jenjang Pendidikan Dasar Dan Menengah, Kementerian Lingkungan Hidup. Jakarta, 2012.

\section{DOKUMENTASI KEGIATAN}

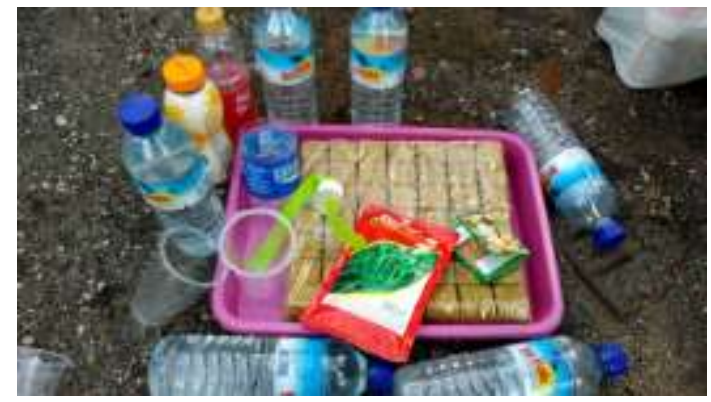

Alat dan bahan yang digunakan sebagai media tanam hidroponik

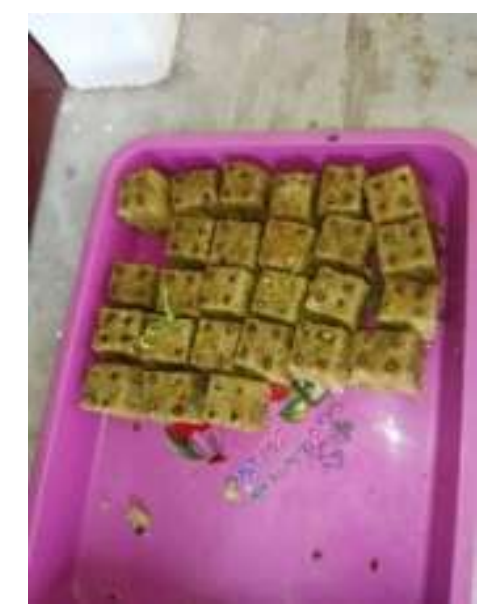

Penyemaian bibit pada media rockwool

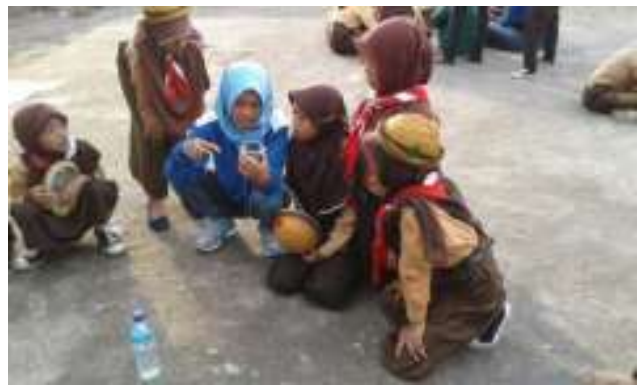

Proses praktikum penanam bibit pada media hidroponik

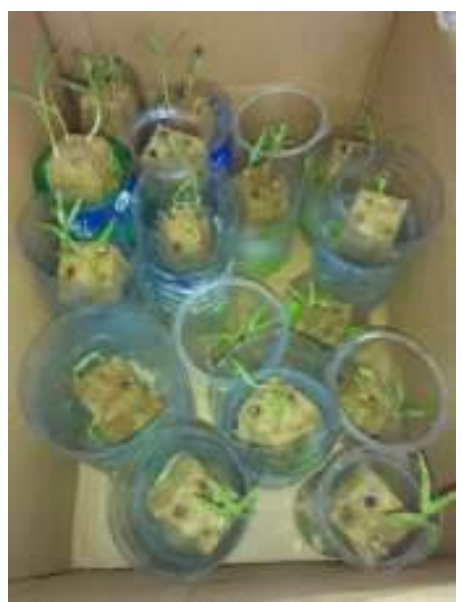

Bibit tanaman yang telah tumbuh dengan baik 